\title{
Positive and Negative Affect Schedule (PANAS): psychometric properties of a Venezuelan Spanish version in medical students.
}

\author{
Trino Baptista1, Olga Vargas ${ }^{2}$, Rosani Colmenares ${ }^{2}$ and Javier Piñero ${ }^{2}$ \\ ${ }^{1}$ Department of Physiology, Universidad de Los Andes Medical School, Mérida, \\ Venezuela. \\ ${ }^{2}$ Department of Psychiatry, Universidad de Los Andes Medical School, Mérida, \\ Venezuela.
}

Key words: affect; feelings; healthy volunteers; reliability; scales; validity.

\begin{abstract}
The study of affect covers a wide range of interests in psychiatry and psychology. The PANAS (positive and negative affect scale) is widely used to explore and monitor affect. In this study, the psychometric features of an online, Spanish version of the PANAS in Venezuela are described. The PANAS comprises 10 items exploring positive (PA) and 10 exploring negative (NA) pointers of affect. After back translation and content validity by expert opinion, the scale was administered to a probabilistic sample of 100 , fifth-year medical students. We assessed factor and internal consistency analysis, 15-day apart test-retest, and concurrent validity with locally validated scales of depression (GE-DEPRE) and anxiety (ANSILET), and the Ryff's scale of psychological well-being (PWB). The PANAS displayed good content validity (validity ratio $=0.91$ ) and internal consistency (Crochan alfa, $\mathrm{PA}=0.89, \mathrm{NA}=0.88$ ). A forced factor analysis produced two, 10-item components of PA and NA each. The PANAS behaved poorly in the test-retest analysis, with marginally significant correlation in the PA dimension only $(\mathrm{p}=0.055)$. The NA subscale positively correlated with the ANSILET scale $(\mathrm{p}=0.03)$ and negatively with the PWB scale $(\mathrm{p}=0.049)$. The PA only showed marginal convergent validity with the "personal relations" dimension of the PWB scale. We confirmed the two dimensions of the PANAS. Its inconsistent repeatability and construct validity support the definition of this scale as a dynamic instrument, relatively independent from depression and anxiety dimensions, and with specific value for monitoring elemental components of affect.
\end{abstract}

Corresponding autor: Trino Baptista. Department of Physiology, Universidad de Los Andes Medical School, Mérida, Venezuela. E-mail: trinbap@yahoo.com 


\title{
Escala de Afectividad Positiva y Negativa (PANAS): propiedades psicométricas de una versión venezolana en español en estudiantes de medicina.
}

\author{
Invest Clin 2020; 61 (4): 301-315
}

Palabras clave: afecto; emociones; voluntarios sanos; confiabilidad; escalas; validez.

Resumen. El estudio del afecto es de interés en diversas áreas de la psicología y la psiquiatría. La escala de afectos positivos (AP) y negativos (AN) (PANAS) explora y monitorea la afectividad. En el presente estudio se describen las propiedades psicométricas de PANAS online en español en Venezuela. Luego de la traducción y evaluación de la validez de contenido mediante el juicio de expertos, se administró la escala a 100 estudiantes del $5^{\circ}$ año de la carrera de medicina. Realizamos análisis factorial, consistencia interna, test-retest a los 15 días, y validez concurrente y divergente con escalas de depresión (GE-DEPRE), ansiedad (ANSILET) y bienestar psicológico de Ryff's (PWBs). La escala demostró buena validez de contenido (coeficiente de validez $=0,91$ ) y consistencia interna (alfa de Crochan, $\mathrm{AP}=0,89, \mathrm{AN}=0,88$ ). $\mathrm{El}$ análisis factorial forzado arrojó 2 factores de 10 componentes cada uno (AP y AN). En el test-retest solo se observó una correlación positiva marǵinal en la dimensión de $\mathrm{AP}(\mathrm{p}=$ $0,055)$. La subescala de AN se correlacionó positivamente con la ANSILET ( $\mathrm{p}=$ $0,03)$ y negativamente con la PWBs $(\mathrm{p}=0,049)$. La subescala de AP solo arrojó correlación positiva marginal con la dimensión de "relaciones interpersonales" de la PWBs $(\mathrm{p}=0,08)$. Confirmamos los dos factores de la PANAS. Las inconsistencias detectadas en la confiabilidad y validez de constructo apoyan la conceptualización de la escala como un instrumento dinámico, con independencia relativa de las dimensiones de ansiedad y depresión y con un valor específico para monitorear componentes elementales de la afectividad.

Received: 22-07-2020 Accepted: 02-11-2020

\section{INTRODUCTION}

The term affect is a psychological construct referring to mental states involving evaluative feelings such as feeling good-bad, liking-disliking a given situation, and several other experiences (1). The scientific study of affect is a crucial topic in contemporary psychiatry, given its relevance for the study of the biological and social basis of mental functions, human relationships, psychopathology, and psychotherapy.
Convergent evidence points at describing the affective experience as constituted by two dominant dimensions: positive affect (PA) and negative affect (NA) (1). Among the available schedules to measure affect, the Positive and Negative Affect Schedule (PNAS) developed by Watson et al., in 1988 (2) is one of the most comprehensive and frequently used. The PANAS is a short while comprehensive, and friendly scale, comprising 10 terms denoting positive affect (PA) and 10 representing negative affect (NA). 
The PA items are interested, excited, strong, enthusiastic, proud, alert, inspired, determined, attentive and active. The NA entries are distressed, upset, guilty, scared, hostile, irritable, ashamed, nervous, jittery, and afraid (2).

Martin Seligman, a leader in contemporary psychology pointed out that many psychotherapeutic schools expect that, in a particular subject, PA and NA balance would spontaneously emerge as psychotherapy progress (3). While this is certainly a fact in some patients, Seligman, among many other authors, strongly advocated for a more active approach in managing affect in the average patient, who surely will improve her core psychopathology, but still would benefit by directly approaching her affect dimension (3). In operational terms it refers to implementing procedures that directly address PA and NA with a relative independence of the specific psychotherapeutic technique. It is here where a reliable instrument for measuring affect has a central role.

The PANAS was originally designed in English in North America, and it has been translated and validated in diverse ethnic groups such as African-Americans (4) and countries such as Argentina (5), Brazil (6), Canada (7), Spain (8), Hungary (9), India (10), Korea (11), Mexico (12), Pakistan (13), Peru (14) and Turkey (15). An online version is available in Spanish (1). In addition to validation studies in healthy subjects, mostly adults, the PANAS has been studied in children (16), subjects with cocaine addiction (17), fibromyalgia (18), in meditation, working memory and meditative training (19-21). There are also some studies about the dynamics of PANAS in subjects with major mentaland personality disorders $(1,22,23)$.

The psychometric and linguistic properties of the PANAS have not been evaluated in Venezuela. This precludes its use in clinical and research settings because the test comprehension is sensitive to specific wording among diverse Spanish-speaking coun- tries $(1,5,12,14)$. We here thus, report the psychometric properties of the PANAS in medical students in Venezuela. For convergent and divergent validity assessment, the scales evaluating depression (GE-DEPRE), anxiety (ANSILET) and psychological wellbeing (Ryff's scale) were used.

\section{METHODS}

The study was designed and conducted in the University Hospital, Universidad de Los Andes Medical School, Mérida, Venezuela, between January and July of 2018. It was approved by the Hospital Ethics Committee; the subjects read and signed an informed consent of voluntary participation.

\section{Validation measures \\ The positive and negative affect scale (PANAS) (2) \\ Translation}

The Mexican version (12) was used as a reference, because most items are similar with those used in Venezuela. A bilingual linguist, who was unfamiliar with the questionnaire, translated the scale back into English. After confirming the correspondence among the original scale (2), the Mexican- and the back-translated versions, two independent, bilingual psychiatrists set the definitive scale. It differed from the Mexican version in the items distressed, upset, scared, hostile, jittery, and afraid. Table I shows verbatim for the original English version and our definitive Spanish version.

The 20 items are rated on a scale ranging from 1 ("very slightly or not at all") to 5 ("extremely"). Subjects are asked to rate how they felt (a) "right now (that is, at the present moment)"; (b) "today"; (c) "during the past few days"; (d) "during the past week"; (e) "during the past few weeks"; (f) "during the past year"; and (g) "in general, that is, on the average" (2). In this study, we used the "during the past week" and "in general" time-frame reference. 
TABLE I

POSITIVE AND NEGATIVE AFFECT SCALE:

ORIGINAL ITEMS IN ENGLISH AND THEIR TRANSLATION INTO SPANISH IN VENEZUELA.

\begin{tabular}{ccc}
\hline Item & Enǵlish term & $\begin{array}{c}\text { Spanish (Venezuelan) } \\
\text { term }\end{array}$ \\
\hline \multicolumn{3}{c}{ Positive affect } \\
\hline 1 & Interested & Motivado \\
3 & Excited & Emocionado \\
5 & Strong & Firme \\
9 & Enthusiastic & Entusiasta \\
10 & Proud & Orgulloso \\
12 & Alert & Alerta \\
14 & Inspired & Inspirado \\
16 & Determined & Decidido \\
17 & Attentive & Atento \\
19 & Activo & Activo \\
\hline & Negative affect \\
\hline 2 & Distressed & Perturbado \\
4 & Upset & Molesto \\
6 & Guilty & Culpable \\
7 & Scared & Asustado \\
8 & Hostile & Hostil \\
11 & Irritable & Irritable \\
13 & Ashamed & Avergonzado \\
15 & Nervous & Nervioso \\
18 & Jittery & Tenso \\
20 & Afraid & Temeroso \\
\hline & &
\end{tabular}

GE-DEPRE; a scale to assess depression

This is a two-factor scale consisting of 16 depression-related items. It was validated in 249 Venezuelan subjects and reported a Cronbach alpha coefficient of 0.88 , and Pearson correlation coefficients of $0.65 \mathrm{vs}$ a scale on aggression, of 0.68 vs an anxiety scale, and of 0.65 vs a general scale of psychological adjustment (24).
ANSILET; a scale to assess anxiety

This is a one-factor scale consisting of 15 anxiety-related items. It was validated in 264 Venezuelan university students and reported a Cronbach alpha coefficient of 0.82 and a Pearson correlation coefficient of 0.59 vs the self-esteem Rosenberg scale (25).

The GE-DEPRE and ANSILET scales were used, since they were designed and validated for university students in our country. Thus, an adequate comprehension of these scales were expected, given a culturally congruent wording in all the instruments. (PWB)

Ryff's scale of psychological well-being

The Ryff Scale (26), validated by Diaz et $a l$., in Spain (27), was used. It comprises six factors: autonomy, environmental mastery, personal growth, positive relations with others, purpose in life, and self-acceptance $(26,27)$. This scale consists of an extended version of 39 items PWB-E and a reduced version of 29 items (PWB-R), this last one included in the former. We administered the 39-item version, but analyzed both, the PWB-E and PWB-R models.

The GE-DEPRE, the ANSILET and the PWB scales were scored with a 6-point likertype scale from $0=$ complete disagreement to $6=$ complete agreement and no neutral score. These scales did not include a cutoff point but are aimed at assessing changes over time in a continuous scale. All the scales are available at request.

\section{Participants and procedure}

The study was conducted in a universe of 190 medical students in their fifth year of their career. This group was selected to improve follow-up, because they were doing their psychiatric clerkship in our Unit. A 100-subject probabilistic sample was obtained by selecting every two names from an alphabetically ordered list. The inclusion/ exclusion criteria were to sign a written consent of voluntary participation, and to have internet availability. 
We personally explained the procedure to the universe sample in a classroom and sent the instruments via e-mail. The participants answered all the scales immediately after reception. Fifteen days later, they only filled the PANAS for the retest procedure, Participants personally returned the informed consent, and this pointed the end of the study. Considering the PANAS, subjects were asked to rate how they felt "during the past week" and "in general, that is, on the average". The other scales implicitly rate how people feel "in general".

\section{Validity and reliability of the PANAS Content validity (evaluation by sub- ject matter experts)}

The PANAS was evaluated by five researchers, all of them psychiatrists, who rated the following three sentences with a 1-7 liker scale, where $1=$ complete agreement and $7=$ complete disagreement:

1. Ten terms of the scale properly explore positive affect.

2. Ten terms of the scale properly explore negative affect.

3 . The 20 items of the PANAS are understandable and are commonly used in Venezuela.

The following formula to get a corrected Content Validity Ratio (CVR $)$ was used (28):

$$
C V R c=\frac{(C V R i)}{N}-(1 / j) j
$$

Where:

$(\mathrm{CVRi}=$ content validity ratio for each item.

$\mathrm{N}=$ number of items (questions).

$\mathrm{j}=$ number of experts.

A GVRe of 0.91 was obtained, which is considered as "excellent" (28).

In the next step, we assessed the PANAS Construct Validity be means of Factor Analy- sis, Convergent and Divergent measures by correlating PANAS scores "in general", with those obtained in the ANSILET, GE-DEPRE and the PWB scale. PANAS reliability was assessed with the Cronbach coefficient of internal consistence and test-retest analysis.

\section{Statistical analysis}

The SPPS IBM 20.0 program was used for factor analysis and Cronbach coefficient calculation. The two-tailed $\mathrm{t}$ test for independent samples and the Mann-Whitney $\mathrm{U}$ test were used to compare between-sex scale scores. The Pearson and the Kendall tau b bivariate correlation coefficients were used for test-retest analysis, convergent and divergent validity analysis. Results were considered significant when $\mathrm{p}<0.05$.

\section{RESULTS}

\section{Sample description}

All the 100 subjects of the estimated sample returned the questionnaires. Near three quarters of the sample were women; age did not differ between sexes: 71 females (71\%; age: [average $\pm \mathrm{SD}]=25.5 \pm 1.7 \mathrm{y})$; 21 men $(21 \%$; age: $25.9 \pm 2.0 \mathrm{y})$. All respondents were single. The authors did not request any other personal information.

\section{Reliability analysis}

\section{Internal consistency}

The analysis was conducted with the data obtained in the first evaluation, referring to the affect assessment "during the past week". Internal consistency Cronbach alpha for the total sample was 0.89 for the PANAS-P and 0.88 for the PANAS-N; for women, PANAS-P $=0.89$; PANAS-N $=0.87$; for men: PANAS-P $=0.87$; PANAS-N $=0.76$. Tables II and III display Cronbach alphas when omitting items, corrected correlations between each item and the total score, and correlations between the items on PANAS-P and PANAS-N, respectively. Most items within each PANAS dimension displayed significant positive correlations, except the association 

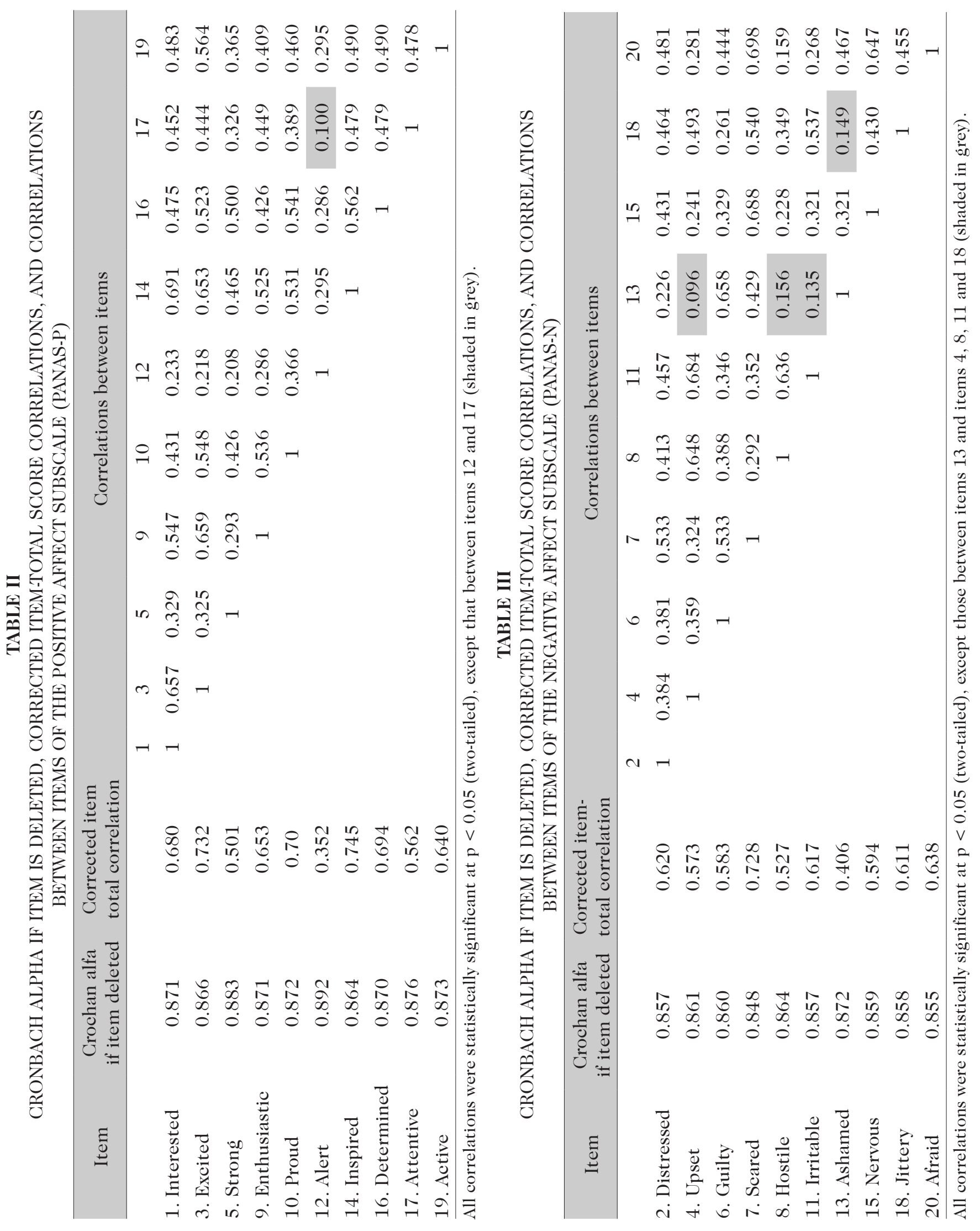
between items 12 (Alert) and 17 (Attentive) in the positive dimension, and between item 13 (Ashamed) and items 4 (Upset), 8 (Hostile), 11 (Irritable) and item 18 (Jittery).

\section{Test-retest}

Participants answered the PANAS at baseline and after 15 days and comprised an affect self-evaluation "during the last week" and "in general". The following Pearson correlations were observed:

\section{Positive affect subscale}

1. First vs. second "during the last week" evaluation: $\mathrm{r}(100)=0.19, \mathrm{p}=0.055$.

2. First vs. second "in general" evaluation: $\mathrm{r}=-0.01, \mathrm{p}=0.9$.

\section{Negative affect subscale}

1. First vs. second "during the last week" evaluation: $\mathrm{r}=-0.09, \mathrm{p}=0.4$.

2. First vs. second "in general" evaluation: $\mathrm{r}=0.08, \mathrm{p}=0.4$.

The analysis discriminating by sex did not show significant or marginally significant correlations between the pre- and post tests (data not shown).

To further explore the reasons behind the low-test stability or repeatability, Table IV shows Kendall tau b correlation coefficients of every item in the first vs. the second evaluation. While the strength of association of the Kendall coefficient is not as straightforward as with the Spearman's correlation coefficient, values between 0.1-0.3 are considered as low; between 0.3-0.5 as moderate and $>0.5$ as strong. Accordingly, the items alert, enthusiastic, excited, inspired, active and interested in the PA side, and guilty, afraid, and distressed in the NA dimension, showed the lowest stability.

\section{Factor analysis}

A principal components analysis (PCA) was carried out on the 20-item PANAS. The suitability of PCA was assessed prior to analysis. The overall Kaiser-Meyer-Olkin (KMO) mea-
TABLE IV

WITHIN-ITEM CORRELATION

IN THE TEST-RETEST EVALUATION.

\begin{tabular}{lccc}
\hline $\begin{array}{c}\text { For every item } \\
\text { (pre vs. post } \\
\text { correlation) }\end{array}$ & Total & Women & Men \\
\hline \multicolumn{4}{c}{ Positive affect } \\
10. Proud & 0.63 & 0.60 & 0.70 \\
17. Attentive & 0.60 & 0.51 & 0.83 \\
5. Strong & 0.58 & 0.60 & 0.60 \\
16. Determined & 0.57 & 0.61 & 0.48 \\
12. Alert & 0.48 & 0.54 & 0.33 \\
9. Enthusiastic & 0.45 & 0.47 & 0.43 \\
3. Excited & 0.45 & 0.47 & 0.34 \\
14. Inspired & 0.42 & 0.41 & 0.43 \\
19. Active & 0.41 & 0.38 & 0.46 \\
1. Interested & 0.33 & 0.37 & $0.20(\mathrm{a})$ \\
\hline & Negative affect & \\
\hline 11. Irritable & 0.67 & 0.74 & 0.53 \\
8. Hostile & 0.63 & 0.62 & 0.67 \\
15. Nervous & 0.61 & 0.63 & 0.57 \\
4. Upset & 0.58 & 0.55 & 0.62 \\
13. Ashamed & 0.56 & 0.55 & 0.59 \\
18. Jittery & 0.56 & 0.56 & 0.55 \\
7. Scared & 0.53 & 0.57 & 0.51 \\
6. Guilty & 0.47 & 0.49 & 0.44 \\
20. Afraid & 0.46 & 0.49 & 0.41 \\
2. Distressed & 0.39 & 0.39 & 0.37 \\
\hline
\end{tabular}

Values represent the Kendall tau b correlation coefficient for every item in the test-rests analysis. For all items except (a), p <0.05.

sure was 0.84 with individual KMO measures all greater than 0.7 , qualifying as 'middling' to 'meritorious' according to Kaiser (1974) (29). Bartlett's test of sphericity was statistically significant $(\mathrm{p}<.0005)$, indicating that the data was suitable for factorization.

PCA revealed three components that had eigenvalues greater than one and which explained $30.2 \%, 20.1 \%$ and $9.5 \%$ of the total variance, respectively. Visual inspection of the screen plot indicated that three com- 
ponents should be retained. In addition, a three-component solution met the interpretability criterion and were retained.

The three-component solution explained $59.7 \%$ of the total variance. A Varimax orthogonal rotation was employed to aid interpretability. The rotated solution exhibited 'simple structure'. The first factor comprised all the ten items considered as indicating positive affect. The second and third factor comprised 7 and 6 items respectively considered ad negative affect (Table V). Component loadings and communalities of the rotated solution are also presented in Table V. The items Alert and Distressed showed the lowest, while significant interitem correlations.
We used the forced factor extraction procedure to obtain two factors. The overall Kaiser-Meyer-Olkin (KMO) measure was 0.83 with individual $\mathrm{KMO}$ measures all greater than 0.7 , qualifying as 'middling' to 'meritorious'. Bartlett's test of sphericity was statistically significant $(\mathrm{p}<0.005)$. Factor one explained $30.2 \%$ of the total variance and comprised the 10 positive-affect items; factor two explained $20.1 \%$ of the total variance and comprised all the ten negative affect items as well. Component loadings and communalities of the rotated solution are presented in Table VI. The item Alert showed the lowest, while significant inter-item correlation.

TABLE V

ROTATED STRUCTURE MATRIX WITH VARIMAX ROTATION OF THE THREE-COMPONENT PANAS.

\begin{tabular}{|c|c|c|c|c|}
\hline \multirow[t]{2}{*}{ Items } & \multicolumn{3}{|c|}{ Rotated component coefficients } & \multirow[t]{2}{*}{ Communalities } \\
\hline & Component 1 & Component 2 & Component 3 & \\
\hline 3. Excited & 0.817 & & & 0.692 \\
\hline 14. Inspired & 0.803 & & & 0.675 \\
\hline 16. Determined & 0.766 & & & 0.589 \\
\hline 1. Interested & 0.756 & & & 0.631 \\
\hline 10. Proud & 0.751 & & & 0.594 \\
\hline 19. Active & 0.729 & & & 0.541 \\
\hline 9. Enthusiastic & 0.721 & & & 0.539 \\
\hline 17. Attentive & 0.642 & & & 0.440 \\
\hline 5. Strong & 0.544 & & & 0.364 \\
\hline 7. Scared & & 0.848 & & 0.777 \\
\hline 20. Afraid & & 0.843 & & 0.724 \\
\hline 15. Nervous & & 0.746 & & 0.610 \\
\hline 13. Ashamed & & 0.677 & & 0.542 \\
\hline 6. Guilty & & 0.659 & & 0.547 \\
\hline 2. Distressed & & 0.551 & 0.437 & 0.501 \\
\hline 3. Upset & & & 0.841 & 0.692 \\
\hline 11. Irritable & & & 0.802 & 0.717 \\
\hline 8. Hostile & & & 0.778 & 0.673 \\
\hline 18. Jittery & & & 0.559 & 0.548 \\
\hline 12. Alert & 0.447 & & 0.531 & 0.486 \\
\hline
\end{tabular}


TABLE VI

ROTATED STRUCTURE MATRIX WITH VARIMAX ROTATION OF THE TWO-COMPONENT PANAS.

\begin{tabular}{lccc}
\hline & Component 1 & Component 2 & Communalities \\
\hline 3. Excited & 0.808 & & 0.658 \\
14. Inspired & 0.801 & & 0.675 \\
16. Determined & 0.767 & & 0.589 \\
10. Proud & 0.758 & & 0.583 \\
1. Interested & 0.744 & & 0.597 \\
19. Active & 0.723 & & 0.525 \\
9. Enthusiastic & 0.721 & & 0.539 \\
17. Attentive & 0.637 & & 0.441 \\
5. Strong & 0.551 & & 0.333 \\
12. Alert & 0.473 & & 0.306 \\
7. Scared & & 0.804 & 0.647 \\
18. Jittery & & 0.728 & 0.534 \\
20. Afraid & & 0.720 & 0.519 \\
15. Nervous & & 0.707 & 0.508 \\
13. Distressed & & 0.704 & 0.501 \\
11. Irritable & & 0.699 & 0.498 \\
14. Upset & & 0.672 & 0.658 \\
6. Guilty & & 0.615 & 0.466 \\
8. Hostile & & 0.607 & 0.402 \\
13. Ashamed & 0.442 & 0.273 \\
\hline
\end{tabular}

\section{Convergent and divergent validity}

The Positive and Negative sections of the PANAS in the "in general evaluation" displayed a negative, significant correlation ( $\mathrm{p}$ $=0.007$ ). Table VII shows data for the whole sample. Results when controlling by sex are described in the text below.

\section{PANAS and anxiety}

The Positive Affect section of the PANAS in the whole sample did not significantly correlate with the ANSILET (Table VII). However, unexpectedly, when discriminating by sex, males showed positive correlations: $r$ (29) $=0.28, \mathrm{p}=0.041$.

The Negative Affect section of the PANAS in the total sample showed a significant positive correlation with the anxiety scale $(\mathrm{p}=0.03)$. When discriminating by sex, the positive correlation was observed only in females: $\mathrm{r}(71)=0.30, \mathrm{p}=0.01$.

\section{PANAS and depression}

None of the PANAS's subscales displayed significant or marginally significant correlations with the depression scale, in the total sample or discriminated by sex (the latter data not shown).

PANAS and the psychological well-being scale

The PA in the total sample only displayed a non-significant, positive correlation with the "positive personal relations" dimen- 


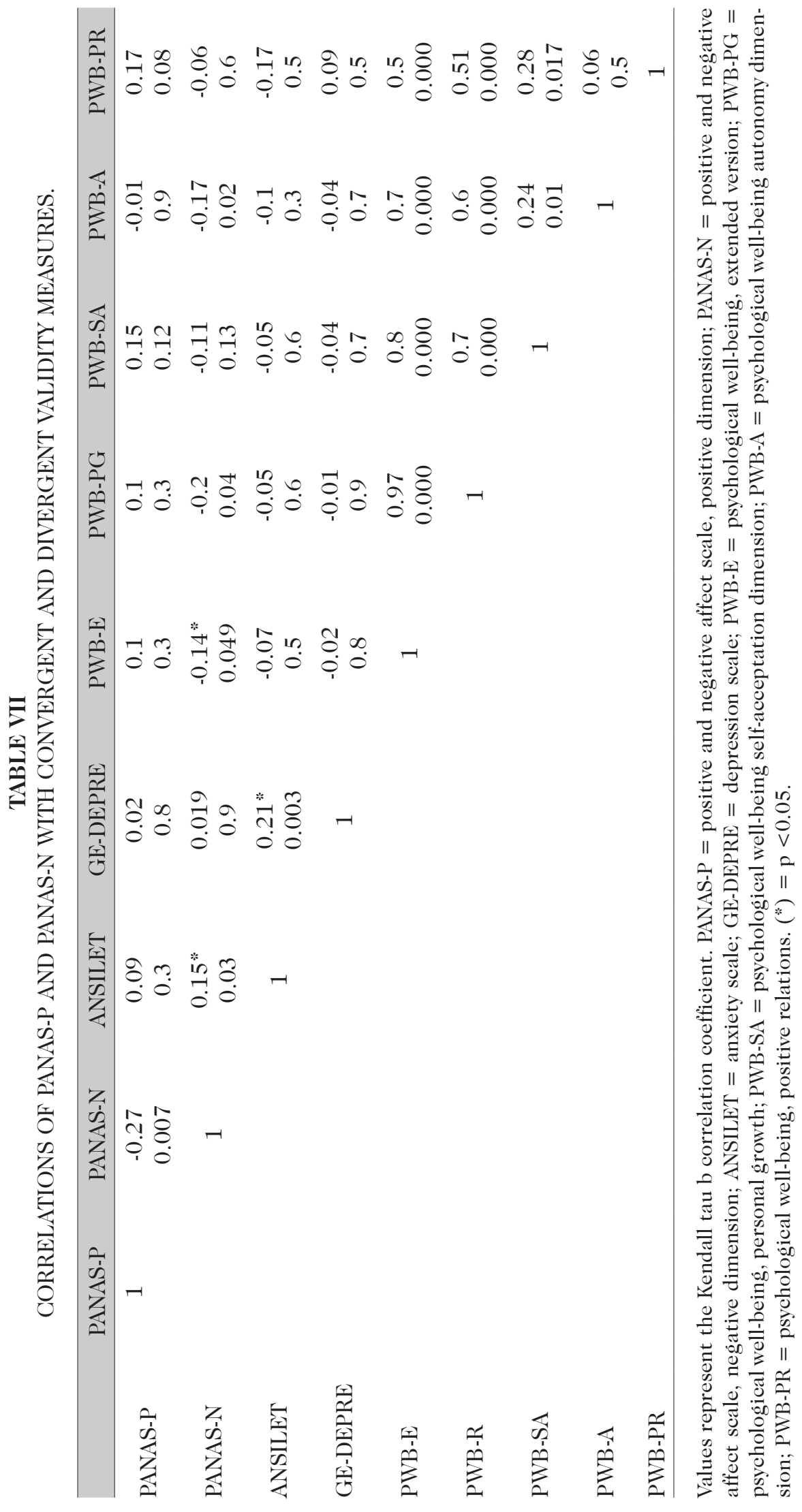


sion $(p=0.08)$ (Table VII). When discriminated by sex, in men the PA only showed a marginal, positive correlation with the PWB$\mathrm{E}: \mathrm{r}=0.33, \mathrm{p}=0.07$, and significant, positive correlations with the PWB-R scale: $(r=$ $0.45, \mathrm{p}=0.014)$. In women, we did not detect any significant or marǵinally signnificant correlation.

The NA subsection in the whole sample showed significant negative correlations with the PWB-E scale $(\mathrm{p}=0.04)$, with the "personal growth" $(\mathrm{p}=0.04)$ and the "autonomy" dimensions $(\mathrm{p}=0.02)$ (Table VII).

When discriminated by sex, in males, the NA subscale showed negative, significant correlation with the "self-acceptance" subscale: $\mathrm{r}(21)=-0.40, \mathrm{p}=0.015$, and marginally significant inverse correlations with the subscales of "positive personal relations": (r $=-0.34, \mathrm{p}=0.064)$ and positive correlation with "autonomy": $\mathrm{r}=0.36, \mathrm{p}=0.053$. In females, the NA subscale showed negative, marginally significant correlations with the PWB-E scale: $\mathrm{r}(71)=-0.22, \mathrm{p}=0.065$, with the "purpose in life" subscale: $r=-02, p=$ 0.09 and significant inverse correlation with that of "autonomy dimension": $r=-0.32, p$ $=0.007$.

Scales scores and correlations with gender and age

The PANAS-P, PANAS-N, anxiety, and depression scores did not differ between the sexes. Men had slightly, but significant higher scores than women in the PWB scale, extended and reduced $(\mathrm{p}<0.05)$ (Table VIII).

In the Pearson correlation analysis, age and PANAS-P scores (in general) positively correlated in the whole sample $(\mathrm{r}(100)=0.27$, $\mathrm{p}=0.006)$ and in females: $\mathrm{r}(791)=0.24, \mathrm{p}$ $=0.046$; in males, the figure reached marginal significance; $r(29)=0.32, p=0.08)$.

No significant correlations were observed between the PANAS-N and age, neither in the whole sample nor when discriminating by sex.

\section{DISCUSSION}

We assessed the psychometric properties of an online, Spanish version of the PANAS. While online and paper scales' administration display strong correlations, they may differ in their psychometric properties (30). Hence, the results obtained in this study will be compared with those of Diaz-García et al. (1), which, to the best of our knowledge, is the only online-administered Spanish PANAS version, and whose psychometric properties have been published. While the two studies are comparable in sex-distribution, -67\% in Diaz-Garcia et $a l$ and $71 \%$ in our sample-, our subjects were all single and aged $25.4 \pm 1.8$ yrs., but theirs were mostly married or lived with a partner, and aged $37.4 \pm 12.5 \mathrm{yrs}$.

TABLE VIII

SCALES SCORES ACCORDING TO SEX.

\begin{tabular}{lcccc}
\hline & Feminine & Masculine & Total & $\mathrm{p}$ \\
\hline PANAS-P & $34.3 \pm 6.8$ & $35.4 \pm 6.7$ & $34.6 \pm 6.8$ & $\mathrm{~ns}$ \\
PANAS-N & $17.6 \pm 7.1$ & $18.9 \pm 6.2$ & $18.0 \pm 6.8$ & $\mathrm{~ns}$ \\
ANSILET & $40.1 \pm 14.6$ & $37.5 \pm 12.9$ & $39.4 \pm 14.1$ & $\mathrm{~ns}$ \\
GE-DEPRE & $34.6 \pm 14.5$ & $33.3 \pm 11.4$ & $34.3 \pm 16.7$ & $\mathrm{~ns}$ \\
PWB-E & $179.3 \pm 17.1$ & $184.4 \pm 7.1$ & $180.8 \pm 15.0$ & 0.037 \\
PWB-R & $133.8 \pm 13.3$ & $138.2 \pm 6.5$ & $135.1 \pm 11.9$ & 0.028 \\
\hline
\end{tabular}

PANAS-P = positive and negative affect scale, positive dimension; PANAS-N = positive and negative affect scale, negative dimension; ANSILET = anxiety seale; GE-DEPRE = depression scale; PWB-E = psychological well-being extended version; PWB-R = psychological well-being, reduced version.

Vol. 61(4): $301-315,2020$ 
Our PANAS version showed an excellent Validity of Content by experts (Content validity Ratio $=0.91$ ), and high Internal Consistence, as assessed by the alfa Cronbach coefficient ( 0.88 for the PANAS-N and 0.89 for the PANAS-P). However, the items Alert, Attentive, in the PANAS-P and Ashamed, Upset, Hostile, Irritable and Jittery, in the PANAS-N, showed low inter-item correlation coefficients. The "Attentive", "Ashamed", "Hostile" and "Irritable" items also showed the lowest correlation in the study of DiazGarcia et al. (1). Hence, these low-correlation items may represent a subset of terms with a rather low comprehensibility in young people, despite attending a very demanding career.

Factor analysis confirmed a two-component model, but a three-component model also emerged, with a main factor of Positive Affect, and two Negative-Affect components. Separate analysis of the small, third negative-affect component, did not improve repeatability or convergent validity (data not shown). The PA and NA subscales correlated negatively (Table VII, $\mathrm{p}=0.007$ ) contrasting with the findings of Watson et al., ${ }^{[1]}$ in the scale development study.

The PANAS repeatability (stability), as measured by the test-retest conducted 15 days apart, only showed marginally significant, positive correlation for the PANAS-P dimension in "the last week" evaluation ( $p$ $=0.055)$. This is surprising, given that tests stability rises with increased temporal aggregation, ${ }^{[2]}$ and a minimal repeatability was rather detected in the short-term aggregation. We do not have a satisfactory explanation of such a low test-retest coefficient and point to a relative independence of the diverse items within each scale dimension. An ordered list of the strength of association within every positive and negative item was presented, and identified those with low test-retest correlations. These items may have been poorly understood by our relatively young sample or might be associated to relatively unstable affect dimensions. Any of the two explanations are of theoretical and practical interest. On the theoretical side, those items require further evaluation and refinement if necessary; on the practical side, such an item instability should be considered when assessing therapeutic interventions.

The PANAS-P subscale showed divergent validity with the Anxiety and Depression scales and a minimal convergent validity with the Psychological Well-Being scales. At this time, there is not a satisfactory explanation for the unexpected positive correlation between the PANAS-P and the ANSILET in male students. We speculate that some PA items such as "alert and active" may have been reciprocally interpreted as "anxiety" by some subjects, and it requires further exploration.

The PANAS-N subscale displayed significant convergent validity with the Anxiety and Well-Being scales, but divergent validity with the Depression scale. The negative PANAS dimension thus, showed better convergent validity than the positive dimension.

The better convergent validity of the negative dimension compared with the positive one contrasts with most studies published so far. For convergent validity assessment and in order to take into account the cultural particularities in wording, we used anxiety (24) and depression (25) scales designed and validated in Venezuela, whereas most studies have used the internationallyused Beck depression or anxiety inventories $(1,2,12)$. Our depression and anxiety scales have not been tested against the Beck's inventories, but they showed a positive, significant correlation with the Zung's depression and anxiety scales (31). In addition, the PANAS was tested in outpatients with minor depression and found negative significant correlations between the PANAS-P and the ANSILET and GE-DEPRE scales and significant, positive correlations between the PANS-N and those depression and anxiety 
scales: $p<0.05$ (Baptista T, personal communication).

Hence, we do not have grounds to suspect that the lack of convergence validity of our PANAS-P could be related to specific features of the external depression and anxiety scales. The PANAS-N subscale by showing significant, negative correlations with the anxiety and well-being inventories, had more consistent properties than the PANAS-P when compared with most previous studies.

The participant sample in this study was constituted by likely healthy medical students under high academic pressure. Hence, this might be associated with increased negative feelings and decreased positive ones, without clear-cut relationships with depression or anxiety, as indirectly suggested by our results.

Nevertheless, importantly, these results agree with the proposal that the PANAS dimensions, while related to mood states, are relatively independent from depression and anxiety, as clinically defined. Hence, it is conceivable that a given subject, while clinically depressed or anxious, still may have a relatively healthy balance of positive and negative feelings. The opposite is also plausible (32). Besides, it is a well-known fact in physiology, psychology and philosophy, that discomfort is more salient than well-being (33). Accordingly, people in a usual, non-reflective state, might be more aware of negative than of positive affect.

However, in the spirit of a comprehensive psychology, the relative dissociation between positive and negative feelings and clinically defined mood disorders, support the use of specific techniques for a simultaneous approach of feelings (affect) and disorders (3).

In summary, the Venezuelan, Spanish version of the PANAS displayed the wellknown, two component model, but also a three-component model, with a small third, negative-affect component. The questionnaire showed good validity content and internal consistence, but low repeatability and convergent validity, particularly the PANAS-
P subscale. Despite a wording close to most Spanish versions, some items showed low correlation coefficients and need further investigation. Two relevant limitations of our study that hampers its generalizability are the sample's young age and the use of anxiety and depression scales validated only in Venezuela.

\section{ACKNOWLEDGMENTS}

This study was the Thesis of Dr. O. Vargas to obtain her tittle of Specialist in Psychiatry, at Universidad de Los Andes, Mérida, Venezuela.

\section{REFERENCES}

1. Díaz-García A, González-Robles, Mor S, Mira A, Soledad Quero A, García-Palacios A, Baños RM, Botella C. Positive and Negative Affect Schedule (PANAS): psychometric properties of the online Spanish version in a clinical sample with emotional disorders. BMC Psychiatry 2020; 20: 56. Doi. org/10.1186/s12888-020-2472-1.

2. Watson D, Clark LA, Tellegen A. Development and validation of brief measures of positive and negative affect: the PANAS scales. J Pers Soc Psychol 1988; 54: 1063-1070.

3. Seligman MEP. Foreword. En: Jeste DV, Palmer BW (Eds). Positive psychiatry: a clinical handbook. American Psychiatric Publishing. Washington DC, 2015, pp. XVII-XIX.

4. Merz EL, Malcarne VL, Roesch SC, Ko CM, Emerson M, Roma VG, Sadler, GR. Psychometric properties of positive and negative affect schedule (PANAS) original and short forms in an African American community sample. J Affect Disord 2013; 151: 942-949.

5. Moriondo M, De Palma $P$, Medrano LA, Murillo P. Adaptación de la escala de afectividad positiva y negativa (PANAS) a la población de adultos de la ciudad de Córdoba: Análisis psicométricos preliminares. Univ Psychol 2012; 11: 187-196.

6. Pires P, Filgueiras A, Ribas R, Santana C. Positive and negative affect schedule: psychometric properties for the Brazilian Portuguese version. Span J Psychol 2013; 16: E58. 
7. Gaudreau P, Sanchez X, Blondin JP. Positive and negative affective states in a performance-related setting. Eur J Psychol Assess 2006; 22: 240-249.

8. Sandín B, Chorot P, Lostao L, Joiner TE, Santed MA, Valiente RM. Escalas PANAS de afecto positivo y negativo: Validacion factorial y convergencia transcultural. Psicothema 1999; 11: 37-51.

9. Gyollai A, Simor P, Koteles F, Demetrovics $Z$. Psychometric properties of the Hungarian version of the original and the short form of the positive and negative affect schedule (PANAS). Neuropsychopharmacol Hung 2011; 13:73-79.

10. Pandey R, Srivastava N. Psychometric evaluation of a hindi version of positive-negative affect schedule. Ind Psychiatry J 2008; 17:49.

11. Lim Y-J, Yu B-H, Kim D-K, Kim J-H. The positive and negative affect schedule: psychometric properties of the Korean version. Psychiatry Investig 2010; 7:163.

12. Robles R, Páez F. Estudio sobre la traducción al español y las propiedades psicométricas de las escalas de afecto positivo y negativo (PANAS). Salud Ment 2003; 26: 69-75.

13. Akhter $\mathbf{N}$. Urdu translation and validation of shorter version of positive affect and negative affect schedule (PANAS) on Pakistani bank employees. J Pak Med Assoc 2017; 67:1517-1523.

14. Gargurevich R, Matos L. Validez y confiabilidad de escala de afecto positivo y negativo (PANAS) en estudiantes universitarios peruanos. Psicología 2012; 14: 208-217.

15. Gençöz T. Positive and Negative Affect Schedule: A study of validity and reliability. Türk Psikoloji Derǵisi 2000; 15: 19-28.

16. Sanmartin R, Inglés CJ, Vincent M, Gonzalvez C, Díaz-Herrero A, García-Fernández JM. Positive and negative affect as predictors of social functioning in Spanish children. PLOS One 13(8): e0201698. Doi. orǵ/10.1371/journal.pone.0201698.

17. Decker SE, Morie, KP, Malin-Mayor B, Nich C, Carroll KM. Positive and negative affect in cocaine use disorder treatment: Change across time and relevance to treatment outcome. Am J Addict 2019; 28:132. Doi: 10.1111/ajad.12716.
18. Cejudo J, García-Castillo FJ, Luna P, Rodrigo-Ruiz D, Feltrero R, Moreno-Gómez A. Using a mindfulness-based intervention to promote subjective well-being, trait emotional intelligence, mental health, and resilience in women with fibromyalgia. Front. Psychol 2019; 10:2541. Doi: 10.3389/fpsyǵ.2019.02541.

19. Pölönen P, Lappi O, Tervaniemi M. Effect of meditative movement on affect and flow in Qigong practitioners. Front Psychol 2019; 10:2375. Doi: 10.3389/fpsyg.2019.02375.

20. Figueira JSB, Pacheco LB, Lobo I, Volchan E, Pereira MG, de Oliveira L, David IA. "Keep that in mind!" The role of positive affect in working memory for maintaining goal-relevant information. Front. Psychol 2018; 9:1228. Doi: 10.3389/fpsyg. 2018.01228.

21. Cunha LF, Pellanda LC, Reppold CT. Positive psychology and gratitude interventions: a randomized clinical trial. Front Psychol 2019; 10:584. Doi: 10.3389/fpsyg. 2019.00584.

22. Mohn C, Olsson AK, Helldin L. Positive and negative affect in schizophrenia spectrum disorders: A forgotten dimension? Psychiatry Res 2018;267:148-153. Doi: 10.1016/j. psychres.2018.05.060. Epub 2018 Jun 2.

23. Kim BN, Kwon SM. The link between hypomania risk and creativity: The role of heightened behavioral activation system (BAS) sensitivity. J Affect Disord 2017; 215: 9-14. Doi: 10.1016/j.jad.2017.02.033.

24. Escalante G. Escala para medir Depresión. Estudio Técnico. Centro de Investigaciones Psicológicas, Universidad de los Andes (ULA); Mérida-Venezuela, 2005. http://www.saber.ula.ve/handle/123456 789/14719. Recuperado el 24-10-2020.

25. Esqueda L. Escala para medir Ansiedad. Estudio Técnico. Centro de Investigaciones Psicológicas, Universidad de los Andes (ULA); Mérida-Venezuela, 1990. http://www.saber. ula.ve/handle/123456789/14719. Recuperado el 24-10-2020.

26. Ryff C. Beyond Ponce de Leon and life satisfaction: New directions in quest of successful aǵing. Int J Behav Develop 1989; 12: 35-55.

27. Díaz D, Rodríguez-Carvajal R, Blanco A, Moreno-Jiménez B, Gallardo I, Valle C, 
van Dierendonck D. Adaptación española de las escalas de bienestar psicológíico de Ryff. Psicothema 2006; 18: 572-577.

28. Hernández-Nieto R. Instrumentos de recolección de datos. Validez y Confiabilidad. Normas y Formatos. Mérida, Venezuela: Consejo de Estudios de Postǵrado, Universidad de Los Andes. 2011. Disponible en https://www.amazon.com.mx/INSTRUMENTOS-RECOLEGCION-DATOS-RafaelHernandez-Nieto-ebook/dp/B007TB4BEE.

29. Laerd Statistics. Principal components analysis (PCA) using SPSS Statisties. Statistical tutorials and software guides 2015. Retrieved from https://statistics.laerd. com/, May 17, 2020.

30. Alfonsson S, Maathz P, Hursti T. Interformat reliability of digital psychiatric self-report questionnaires: a systematic review. J Med Internet Res 2014; 16 (12): e268.
31. Suarez B, Serrano A, Cova Y, Baptista T. Isotretinoin administration was not significantly associated with depression or anxiety in acne-treated patients: a 12-week, fixeddosage prospective study. World J Psychiat 2016: 6: 136-142.

32. Summers RF, Lord JA. Positivity in supportive and psychodynamic therapy. In: Jeste DV, Palmer BW (Eds). Positive psychiatry: a clinical handbook. American Psychiatric Publishing. Washington DC, 2015, chap. 9.

33. Baptista T. Psychotherapists: Should we meet Arthur Schopenhauer? Invest Clin 2016; 57: 409-426. 